\title{
The Life Course of Methamphetamine Users in Aotearoa/New Zealand: The Role of Romantic Relationships and Parenting
}

\author{
Trent Bax \\ Sociology Department, Ewha Womans University, Seoul, South Korea \\ Email: trentbax@hotmail.com
}

How to cite this paper: Bax, T. (2021). The Life Course of Methamphetamine Users in Aotearoa/New Zealand: The Role of Romantic Relationships and Parenting. Open Journal of Social Sciences, 9, 135-153. https://doi.org/10.4236/jss.2021.97009

Received: April 2, 2021

Accepted: July 13, 2021

Published: July 16, 2021

Copyright $\odot 2021$ by author(s) and Scientific Research Publishing Inc. This work is licensed under the Creative Commons Attribution International License (CC BY 4.0).

http://creativecommons.org/licenses/by/4.0/

\begin{abstract}
This paper seeks to improve understanding of how romantic relationships and parenting influence illegal drug using trajectories, and, conversely, how illegal drug use impacts on romantic relationships and parenting. This analysis is part of the first life course-based qualitative study of former methamphetamine users in Aotearoa/New Zealand. Laub and Sampson's "age-graded theory of informal social control" is applied to data from in-depth semi-structured interviews with 35 former methamphetamine users. Analysis shows that support for the theory is relatively weak in regards to relationships (especially females), yet strong for parenting. Compared to romantic relationships, parenting is less likely to increase illegal drug use and much more likely to decrease illegal drug use. Methamphetamine exerted the most negative influence on romantic relationships and parenting. Additionally, female interviewees encountered much greater adversity in their relationships and parenting. Overall, the male partner was more likely to influence increased drug use among the female partner, whereas the female partner was more likely to influence decreased drug use among the male partner.
\end{abstract}

\section{Keywords}

Methamphetamine Use, Aotearoa/New Zealand, Romantic Relationships, Marriage, Parenting

\section{Introduction}

According to the "Harvard Study of Adult Development", one of the world's longest studies of adult life, happiness and a flourishing life rest on two main pillars. One pillar is love, and the other pillar is "finding a way of coping with life 
that does not push love away" (Vaillant, 2012: p. 50). By concluding "happiness is love" (Vaillant, 2012: p. 52), this 75-year longituduinal study clearly shows lives are greatly enriched by loving relationships. By contrast, the study also found that those with an impaired capacity for intimacy were much more likely to use mood altering drugs to "soothe themselves" (Vaillant, 2012: p. 143). According to Ministry of Health data (2014; 2016; 2019a), approximately 1\% of Aotearoa/New Zealanders used methamphetamine in the previous 12-months, while about $0.2 \%$ or 10,000 individuals use methamphetamine on a monthly basis. The same data also shows methamphetamine use among males is two-to-three times higher than females; those aged 25 - 44 use methamphetamine at a higher rate than other age groups; Māori are two-to-three times more likely to have used methamphetamine than European/Pākehā; while about five times more people living in the most deprived neighbourhoods use methamphetamine than those living in the least deprived neighbourhoods. While methamphetamine use in Aotearoa/New Zealand is relatively uncommon and unequally distributed, it nevertheless has the potential to negatively affect individuals, families and communities. Frequent methamphetamine use can potentially increase the risk of cardiovascular and mental health problems, particularly anxiety, mood swings and paranoia, and has been associated with violent behaviour for those with existing mental health problems and a predisposition for violence (Policy Advisory Group, 2009). Methamphetamine use is also intimately connected to criminal activity, which harms community cohesion. For example, 36\% arrested for a criminal offense in 2015 reported using methamphetamine in the previous 12 months (Johnson, 2018). Moreover, survey results from 2010 to 2016 indicate between $33 \%$ - 56\% of frequent drug users purchased methamphetamine from a gang member or gang associate (Wilkins et al., 2017). And in 2017, the Police Association claimed methamphetamine to be the biggest driver of crime in eleven of the twelve police districts (Clayton, 2017b).

More broadly, the 2018 government inquiry into mental health and addiction found one-in-five Aotearoa/New Zealanders experience mental health and addiction challenges at any given time (Paterson et al., 2018). Since citizens noted too many children grow up in a "toxic environment" of "multigenerational trauma, family violence, poverty, abuse and neglect", then intervening early to prevent adverse childhood experiences was seen as the "best medium- to long-term investment in mental wellbeing” (Paterson et al., 2018: p. 50). The inquiry also noted future research on Aotearoa/New Zealand's drug users should "engage more fully with life-course theory" and a "life-course approach" (Paterson et al., 2018: p. 50; 83). While government policy needs to be guided by evidence, at present there is a serious lack of research on methamphetamine users in New Zealand. This IRB-approved ${ }^{1}$ research is a direct response to that call by providing the first life course-based qualitative study of frequent methamphetamine users in Aotearoa/New Zealand. While this government inquiry is correct to promote wellbeing early in life to tackle the social determinants of mental ${ }^{1}$ Approved by “Ewha Womans University Institutional Review Board", at Ewha Womans University. IRB\#: 158-6. 
health and substance use challenges, better understanding is also required regarding stability and change in drug use patterns over the whole life course. This is because there are important differences in adult delinquent trajectories that cannot be predicted from childhood (Laub \& Sampson, 2003). Simply, as individuals age and their social roles change, experiences and events at each stage of the life-course influence drug use patterns (Teruya \& Hser, 2010). With greater knowledge of the social processes underlying methamphetamine use over the life-course, this research has the potential to help improve prevention, intervention, and treatment programs for Aotearoa/New Zealand's methamphetamine users.

\section{Age-Graded Theory of Informal Social Control}

Sampson and Laub's (1993) age-graded theory of informal social control emphasizes the importance of interpersonal social bonds at all ages across the life course. Such bonds link individuals to one another and to wider institutions of informal social control such as family, school, work and the community. The theory posits that deviance and crime are more likely to occur when a person's bond to conventional society is weak or broken. A key component of the theory is incorporating both stability and change in deviant and criminal behaviour over the life course. On the one hand, childhood experiences are important for understanding behavioural stability, yet experiences in adolescence and adulthood can redirect delinquent and criminal trajectories in either a more pro-conformist or anti-conformist manner. Laub and Sampson argue job stability and marital attachment are significantly related to changes in adult criminal behaviour. Simply, the stronger the adult bonds to work and family, the less deviance and crime. Thus the theory postulates that transitional life events (e.g., marriage, parenting) and specific social bonds (e.g., a cohesive marriage, close attachment to children) can function as turning points to "knife off" delinquent trajectories set earlier in life. By contrast, they found persistent adult offenders lead unstructured and chaotic lives across multiple dimensions (specifically living arrangements, family and work). This implies situational context is important for understanding patterns of stability and change in deviant and criminal behaviour over the life course.

Prior analysis by the author (Bax, forthcoming) on the family environment of 41 former methamphetamine users discovered participants had encountered approximately five adverse childhood experiences on average, and that almost three-quarters had encountered four or more ACEs. Such cumulative adversity indicates prosocial authoritative parenting practices during childhood are important to help avert the developmental pathway of frequent substance use from unfolding (Patterson, 1980). A subsequent analysis (Bax, 2021) expanded the scope of the inquiry to include the life domains of school, friendship and work. This analysis discovered 20 commonly shared adverse experiences that hindered educational and employment success and contributed to drug use. With 12 of these 20 adverse experiences related to school, and with the significance of de- 
linquent peer involvement contributing to drug use, this analysis highlights the importance of improving educational outcomes to alter drug use trajectories, especially in high school, and especially for male and Māori students. The present analysis expands the scope even further by analysing the interviewees' romantic relationships and parenting situation. This allows a better understanding of how romantic relationships and parenting influence illegal drug using trajectories and how, in turn, illegal drug use impacts on romantic relationships and parenting.

Laub and Sampson (2003) argue the behavioural change that results from a marriage is due to an enduring attachment that gradually grows over time. The growth of this social bond is akin to an investment process, for as the investment in the bond grows the incentive for avoiding deviancy and crime increases because more is at stake to lose. The marriage bond creates an interdependent system of responsibility and restraint, and as social capital accumulates so too does the inhibition to engage in deviance and crime. Additionally, marriage can change one's sense of self because it entails "getting serious" and "becoming an adult" (Laub \& Sampson, 2003: p. 43), while becoming a parent increases "a sense of maturity and responsibility” (Laub \& Sampson, 2003: p. 136). Marriage and parenting responsibilities also lead to meaningful changes in routine activities. As more time is spent in structured family-centred activities, less time is spent in unstructured leisure activities outside the family, especially with deviant peers (Warr, 1998; Shover, 1996). Importantly, Laub and Sampson (2003) concur with Horney, Osgood and Marshall (1995) who found marriage and cohabitation differ with respect to their crime suppression effects. While marriage reduces delinquency and crime, cohabitation does not, and may actually increase deviant and criminal behaviour.

Thus illegal drug users will be inhibited from using drugs to the extent they accumulate social capital in their stable marriage relationship. Conversely, if marriage is absent, or characterized by weak attachment, or if an individual is divorced, separated, single or in an unstable relationship, continued illegal drug use will occur (Roe et al., 2010). The same rule applies to parenting, which is assumed to have a "civilizing effect" on deviants and criminals, especially men (Popenoe, 1996).

Drug use research clearly shows drug use trajectories are linked to changes in social roles, with problematic drug use associated with loss of conventional roles and relationships (Levy \& Anderson 2005; Boeri \& Walen, 2012). When drug users become more immersed in the drug-user role their bond to conventional social roles, specifically legitimate worker, spouse, parent, weakens or even breaks. If they become less committed to or severe their bonds to that conventional role, then time spent in the drug using role is predicted to increase (Becker, 1963; Biernacki, 1986; Boeri, 2004). Therefore, frequent illegal drug users must learn to control their drug use in order to fulfil their conventional role-related behaviour (Boeri, Sterk, \& Elifson, 2006). Various studies have found marriage (Curran at al., 1998), the quality and duration of a marriage 
(Hser, Longshore, \& Anglin, 2007), romantic relationships (Boshears, Boeri, \& Harbry, 2011), caring relationships (Moneyham \& Conner, 1995), meaningful family attachments (Peele, 1989), a stable home environment (Granfield \& Cloud, 1996), having a child (Granfield \& Cloud, 2001) and becoming a parent (Peele \& Rhoads, 2019) can function as turning points to knife off drug use trajectories. The data indicates individuals "mature out" of frequent drug use when they form stable, mature relationships and/or become parents (Peele \& Rhoads, 2019: p. 131). Simply, individuals who have a "stake in conventional life" and greater social capital are better able to alter their drug-taking practices. Conversely, those with less social resources, and who have less or nothing to lose by their drug use, are most likely to continue drugs use (Granfield \& Cloud, 1996).

\section{Life Course Method}

By integrating personal, social and environmental factors, the life-course method focuses on changes in relationships and behavior as people twist and turn along the pathway of life, and how, in turn, these changes affect behaviours such as drug use patterns. The life-course approach recognises the mutual influence of person and social context over time (Giele \& Elder, 1998). Since people are influenced by, and, in turn, influence others, the life-course approach also recognises the bi-directional nature of relationships (White Riley, 1998). Ideally, a life-course approach seeks to obtain data on: human agency (health, wellbeing, and subjective aspects of meaning and satisfaction); linked lives (relationships in family, school, work, friendship, marriage and other social domains); timing (event histories in these major domains of activity), and; location (social, cultural and historical context) (Giele \& Elder, 1998).

The life-course method offers an expanded organizing framework that allows researchers to account for the trajectories, transitions and turning points that characterize the life-course of methamphetamine users (Hser, Longshore, \& Anglin, 2007; Boeri \& Whalen, 2012; Teruya \& Hser, 2010). Additionally, a retrospective person-based life-history narrative approach reveals in the drug user's own words the personal-situational context of their behaviour, thereby revealing the interconnectedness between life events and situations (Laub \& Sampson, 2003). What gives the life course approach its life is the sentient individual who is: 1) encountering new circumstances and relationships, 2) going through important life changes, and 3) deciding whether to continue on the present trajectory or change their life course. After all, it is this socially situated sentient individual who is "integrating events and experiences and giving them meaning" (Giele \& Elder, 1998: p. 184). The data acquired for this research is as follows (Table 1).

In this paper, only data from the 35 semi-structured interviews is used. The interviews, conducted in 2018, were divided into two parts: 1) Life in Review (containing 35 questions), and 2) Methamphetamine Use (containing 30 questions). In Part 1, interviewees were asked to review their life from beginning to 
Table 1. Data source.

\begin{tabular}{|c|c|}
\hline $\mathbf{N}$ & Primary Data (obtained via snowballing method) \\
\hline 35 & $\begin{array}{l}\text { In-depth semi-structured interviews with former methamphetamine users } \\
\qquad(100 \text { hours of recorded data) }\end{array}$ \\
\hline 6 & $\begin{array}{l}\text { In-depth unstructured interviews with mother/wives/ex-wife/partner/former-partner of } \\
\text { former methamphetamine users ( } 10 \text { hours of recorded data) }\end{array}$ \\
\hline & Supplementary Data (obtained via an online methamphetamine support group) \\
\hline 6 & Transcribed testimonies of former methamphetamine users ( 7 hours of video data) \\
\hline 18 & Transcribed live online chats with former methamphetamine users ( 20 hours of video data) \\
\hline 65 & Approximately 1 million words of transcribed empirical data \\
\hline
\end{tabular}

present, including the following domains: family; school; friendships; work; romantic relationships; marriage; parenting; psychological health; physical health; religion/spirituality. Interviews focused on the significant relationships, experiences and events in each of the above life domains in order to understand the trajectories, role transitions and turning points in their life. Participants were also asked about their drug use history (except methamphetamine), and at the end of each life domain were asked whether that domain has influenced their drug use, and, reciprocally, whether drug use has impacted on that life domain. Part 2 focused specifically on their methamphetamine use, including onset, progression, control, impact, desistance and life post-methamphetamine use. On average, each interview lasted approximately three hours. Regarding the 41 interviews, contact was initially made with five former methamphetamine users known to the author. A snowballing method was used to locate 22 other interviewees, while the remaining 14 were located through advertisements posted on two online methamphetamine support groups. The interview location was chosen by the interviewee, and included private homes, commercial establishments, public spaces and work.

Participants were born between 1962 and 1995 (with half born in the 1970s), and 43 -years-old on average. Additionally, 54\% are male, $46 \%$ female, $74 \%$ European/Pākehā and 26\% Māori (the general population is $49 \%, 51 \%, 70 \%$ and $16.5 \%$ respectively). Regarding residence, participants have lived throughout all of Aotearoa/New Zealand's provinces in various villages, towns and cities. Regarding socioeconomic-status, distribution largely accords with the 2006 Aotearoa/New Zealand socio-economic index (Milne, Byun, \& Lee, 2013). Despite the sample size, the interviewees" sociodemographic characteristics are broadly reflective of the general population. To qualify as a former frequent methamphetamine user, participants had to have used methamphetamine for at least six consecutive months, but had not used for at least 12 months. On average, interviewees were frequent methamphetamine users for seven-and-a-half-years, and ceased being a methamphetamine user seven-year prior to the interview at age 36. All interviewees also have an extensive and varied history with other legal and illegal substances. All have used alcohol and cannabis at least once (begin- 
ning at age 14 on average). Approximately three-quarters have used nicotine, LSD and amphetamine. Approximately half have used magic mushrooms and ecstasy, and one-third cocaine. However, only nine have used an opioid (opium, heroin or methadone) and only seven have used ketamine, benzodiazepine or gamma-Hydroxybutyric acid (GHB). On average, each has used six of these 14 substances over the past 14 to 43 years.

\section{Romantic Relationships}

\subsection{Number of Serious Relationships}

Interviewees were initially asked, "Can you tell me about the serious relationships you have had in your life?" Other than two homosexual men and two bisexual women, all other interviewees are heterosexual. The number of serious relationships was divided into three categories: 1) only one relationship, 2) between two and five serious relationships, and 3) six or more serious relationships. Only three interviewees have had only one serious relationship to date, and all three are male. Conversely, five interviewees have had six or more serious relationships, and they are all female. The vast majority (27-out-of-35) have had between two and five serious relationships during the past 15 to 35 years, with 2.8 relationships per person on average. Age of onset of their first serious relationship ranges from 14 to 25 and is 17.8 years of age on average (although 16.2 for females and 19.1 for males). By way of comparison, the 2014/15 New Zealand Health Survey indicates males aged 16 - 44 have had, on average, 11 heterosexual sexual partners and first had heterosexual sex at age 17.4, whereas females have had eight heterosexual partners and first had heterosexual sex at age 17.2 (Ministry of Health, 2019b).

\subsection{Relationship Status}

The interviewees' past and current relationship status was analyzed. Over one-third of the males and half the females have yet to marry. This is not due to age, as the average age of 40 is approximately 10 -years older than the national age at first marriage (Clayton, 2017a). Of the twenty who have married, half divorced between ages 23 and 47. By contrast, only 19\% of Aotearoa/New Zealanders in 2010 had divorced or separated by age 49 (DePaulo, 2019). The average age at divorce was just prior to their $35^{\text {th }}$ birthday, which is 10 -years earlier than the national median age at divorce (Clayton, 2017a). The current marriages began 3 to 34 years prior to the interview, and on average were in their $14^{\text {th }}$ year. For 9-of-the-13 current marriages, the interviewee remained married during and after methamphetamine use (and 7-of-the-9 were male). Four of these husbands secretly used methamphetamine for at least 4-years behind their partner's back, while two husbands and two wives used methamphetamine with their spouse. Despite the strain methamphetamine use placed on the marriage, 8-of-the- 9 were in relatively stable and loving marriages (and for seven the relationship began prior to methamphetamine use onset). 
At the time of the interview, over half the males were in a marriage relationship, while almost a quarter were in a cohabiting relationship. By contrast, only three females were married, while just two were in a cohabiting relationship. Thus over three-quarters of the males were either in a relatively stable marriage or long-term relationship, while over two-thirds of the females were single. Overall, the females are more likely to have never married and to have divorced, and much more likely to be single; nevertheless, all managed to desist from methamphetamine use. Of the nine Māori interviewees, one was married and four were in a relatively stable long-term relationship at the time of the interview. Despite two having divorced, seven yet to marry, and four being single, all managed to desist from methamphetamine use.

\subsection{Relationship Stability}

The underlying nature of the interviewees' relationships, in particular stability, was also analyzed. One-third of the males, but only two females, have been in relatively stable long-term relationships. Additionally, just over one-third of both males and females have been involved in relatively unstable long-term relationships. The remaining one-third of males and half of females have been involved in multiple relatively unstable medium-term relationships. Of the two-thirds of males and 14-of-the-16 females involved in relatively unstable relationships, 8-of-the-13 males, but only one female, was able to find a relatively stable relationship post-methamphetamine use (5-of-the- 9 are marriages, and five began after desisting from methamphetamine). Of the Māori interviewees, only one experienced a relatively stable long-term relationship, while three settled down into a relatively stable relationship with an existing or new partner. Regarding infidelity, three-times as many males cheated on their partner, while almost three-times as many females were cheated on by their partner.

\subsection{Volatile and/or Violent Relationships}

Over two-thirds of all interviewees have been involved in volatile and/or violent relationships. All but one of the females has been involved in a volatile and/or violent relationship, which is double that of male involvement. While all but one of the female interviewees was a victim of domestic violence, only two male interviewees were. Over half of the males involved, but none of the females, was more likely to have been the perpetrator. All the partners of the female victims were also frequent drug users (with 9-of-the-15 also methamphetamine users).

These abusive male partners could be "unbelievably controlling", "very manipulative", "very overpowering" or "very jealous and protective". For example, the ex-husband of Interview-5 (female, 50-years-old) believed he "owned me" because "he had spent that time reeling me in". Likewise, the ex-partner of Interview-30 (female, 36-years-old) believed "I was his property" and "sex slave" that he "owned". Female interviewees variously described their "complex" partner as "very troubled", an "abusive narcissist", a "serial cheater", a "violent alcoholic", a "career criminal", a "freak", or a "real psycho". This partner would 
"abuse me", "push me", "yell and scream at me", "treat me like shit" or "drink a lot and beat me up". He also "punched me in the head" or "bashed the living shit out of me". One interviewee was "held at knifepoint for 6 hours" while another was "held at knifepoint for 8 hours". The ex-husband of Interview-5 (female, 50-years-old) "poured petrol on me and kicked the shit out of me" whilst threatening to light her on fire. When high on methamphetamine, the ex-boyfriend of Interview-24 (female, 42-years-old) "chased me around the table with a big knife and was going to stab me" after he discovered she had secretly aborted their child. These "trauma inducing" relationships variously "stripped away at my core", "broke my heart and shattered it into pieces" or "made me turn into a crazy person". Domestic life became "miserable" or "just violence", or the interviewees' "self-esteem and mental health went down". Female interviewees variously felt "used", "abused" or "taken for granted", or it "became increasingly harder to hold it together and function as a decent human being". Interview-7 (female, 49-years-old) found it very difficult to leave her now ex-partner because she was "so downtrodden" and "trauma bonded to him".

\subsection{The Influence of Romantic Relationships on Drug Use}

Interviewees were asked, "Do you think your romantic relationships influenced your drug use?” Analysis indicates romantic relationships contributed to both increase and decrease drug use. For three-quarters, the relationship contributed to increase alcohol consumption, illegal drug use and/or methamphetamine use. For two females (one of whom was in a stable marriage), the relationship influenced only their methamphetamine use their male partner introduced them to and supplied them with methamphetamine. And in only two cases did the interviewees' romantic relationship only have a positive influence on decreasing drug use (in both cases the non-drug using wife helped the male interviewee desist from methamphetamine use, although only one was in a stable marriage). Where the relationship did not noticeably increase their drug use, all seven were male (yet only one was in a stable marriage during methamphetamine use). Overall, the male partner was more likely to influence increased drug use among the females, whereas the female partner was more likely to influence decreased drug use among the male partner.

Expectedly, all fourteen females in a relatively unstable relationship saw the relationship contribute to increased use; however, that is true for only 7-of-the-13 males in relatively unstable relationships. Unexpectedly, 6-of-the-8 long-term stable marriages contributed to increase drug use. The most common reason for increased use (present in 21-of-26 cases) was having a partner who was accepting of, or encouraged, drug use. This reason was more common among the females. Prior research (Hser, Longshore, \& Anglin, 2007) has shown the drug use pattern of the partner influences whether or not marriage produces a positive shift on a drug use trajectory. The second most common reason (present in over half) was using alcohol, cannabis, LSD, ecstasy and/or methamphetamine as a 
"coping mechanism" to either "self-medicate", "deal with", "escape from", "endure" or "block out" their partners' abuse, cheating, control, manipulation, pressure, suicide, death and/or a failing marriage. This factor was much more common among the females, and expectedly only included 1-of-the- 8 in a stable marriage (vs. 13-of-the-27 in an unstable relationship). Research by Boeri, Harbry, \& Gibson (2009) also found psychological turmoil and romantic relationship problems increased methamphetamine use. The third most common reason was the partner introducing the interviewee to drugs (which is also in line with Boeri, Harbry, \& Gibson's findings). In 9-of-the-11 cases it was the female interviewees' partner who introduced her to illegal drugs. This finding resonates with the theory that females are "most often led into" drug use by a male partner (Peele \& Rhoads, 2019: p. 98). Similarly, in the six cases where the partner supplied the drug, all of them were the female interviewees' partner. The only factor where males were overrepresented was when drug use was considered a "mutual interest" or was used for "having fun" (likewise, Boeri, Harbry, \& Gibson's research found having fun to be a common reason for young adults to start methamphetamine use). Moreover, illegal drugs, but especially methamphetamine, was used for sexual activity in at least six cases. The least common factor consisted of two male and two female interviewees (in unstable relationships) being pressured, forced or coerced to use methamphetamine. Overall, methamphetamine exerted the most negative influence on the relationship; for half of them, methamphetamine use greatly contributed to the relationship almost terminating or terminating.

For over half the interviewees, the relationship helped to limit or decrease drug use. Surprisingly, this decrease was just as likely to occur whether the relationship was unstable or stable, it occurred in 12-of-the-27 unstable relationships and 4-of-the-8 stable marriages. The most common reason was having a partner who provided support to help either decrease or desist from drug use. In all eight cases it was the male interviewee's female partner who provided this support (and seven were in a stable marriage or relationship at the time they received this support). Also present in over one-third of these cases was having a partner who was either a non-drug user or who disapproved of drug use. While only 3-of-the-7 were in a stable marriage at the time, this reason either helped to restrict drug use, contributed to desistance, or helps maintain the state of desistance. Then the partner either threatening to leave, or leaving, helped three interviewees quit drug use (including methamphetamine). Moreover, two female interviewees had a controlling male partner who controlled her drug use, thereby limiting consumption. Finally, a male cheating on his partner, a husband violently abusing his wife, and a female being violently abused by her partner, each acted as the main catalyst for desisting from methamphetamine use.

\subsection{The Influence of Drug Use on Romantic Relationships}

Interviewees were then asked, "Do you think your drug use impacted on your 
romantic relationships?" In only 3-of-the-35 cases did drug use not negatively influence at least one serious relationship. For 16-of-the-35, alcohol, illegal drugs, and/or methamphetamine negatively influenced the relationship, whereas for an equal number it was only methamphetamine that impacted negatively (indicating methamphetamine's disproportionate impact on the relationship relative to other drugs). For 13-of-the-35, their alcohol, illegal drug use and/or methamphetamine use had a partially positive influence on the relationship. But in no case did drug use only have a positive influence on the relationship. Drug use had a negative impact on all eight stable marriages, but also had a partially positive influence on half (it helped to strengthen their marriage). Likewise, drug use had a negative impact on 24-of-the-27 unstable relationships, although it also had a partially positive influence on almost one-third (they were more loving when high on methamphetamine).

As to the six main reasons why alcohol, illegal drugs and/or methamphetamine use negatively impacted on the relationship, in 21-of-the-32 cases drug use contributed to the relationship nearly terminating or terminating (in 19 cases methamphetamine was the main drug). This reason was present in only 3 -of-the- 8 stable marriages. Then in 13-of-the-32 cases their drug use made them treat their partner in a more negative way, which caused "issues" in the relationship such as "hurt", conflict, and emotional and/or physical distance (methamphetamine was involved in all thirteen cases, and present in 3-of-the- 8 stable marriages). Then in 10-of-the-32 cases the relationship with a drug using partner was, upon reflection, considered "fake" in quality because it was "based around drugs". This reason, more common among the females, led to a "false happiness" and distorted sense of love (methamphetamine was involved in all ten cases). Also in 10-of-the-32-cases the partner did not like the interviewee using methamphetamine, which led to them concealing their methamphetamine use from their partner and then living a deceit-based "double life". Then in 9-of-the-32 cases, but only in one of the stable marriages, methamphetamine use with their partner led to conflict, abuse and/or victimization during the comedown period. For Interview-5 (female, 50-years-old), the comedown "turned us both into monsters". For Interview-30 (female, 36-years-old), the comedown "brought the evil out of $m e$ ". And for six female interviewees drug use either made it "more acceptable" to endure an abusive relationship, or led to forming a relationship with an abusive drug user and dealer.

As to the three main reasons why alcohol, illegal drugs and/or methamphetamine had a partially positive influence on their relationship, in 8-of-the-13 cases they were "really loving" or "nice" to each other or had "fun" or "fantastic sex" when high on methamphetamine. For Interview-8 (female, 49-years-old), being high on methamphetamine was "the only time we interacted like a loving couple". But during the comedown, these couples, all of whom were in an unstable relationship, either "hated each other", or acted like an "asshole", or became "really abusive", or the relationship returned to "shit" or "rubbish". However, for four interviewees methamphetamine use with their spouse brought them closer 
together and helped strengthen their long-term stable marriage.

\section{Parenting}

Regarding parenting, interviewees were initially asked, "Tell me about having a child/children and your experience of being a parent. What was, and is, your relationship like with your child/ children?" 28-of-the-35 interviewees have had 76 children between them, ranging from 1 to 34 -years-old. On average, they have 2.7 children with an average age of 14 . Two-thirds of those with children including 8-of-the-9 Māori interviewees had at least one child outside of wedlock (and three-quarters had all their children outside of wedlock). Additionally, almost half had children with multiple partners (with two-thirds being female). Among the 21 with at least two children, in only eight cases were all children born to the same partner (and seven of these are male interviewees). Likewise, of the 13 who had some or all their children to their current partner, 10 of them are male interviewees. Thus female interviewees were more likely to have a child outside of marriage and to have had children to multiple partners, and much less likely to have had children born to the same partner and/or their current partner.

\subsection{Relationship with Children}

The underlying nature of interviewees' relationship with their children, and the role of the other parent, was analyzed. Slightly less than half have had a consistently close relationship with all their children (and they include 6-of-the-7 in stable marriages with children). Nevertheless, only two have had a consistently distant relationship with all their children. Additionally, five males saw their relationship with all their children become, over time, either more distant (due to entering methamphetamine use or physical separation) or closer (due to exiting methamphetamine use). It was more common, especially for the females, to have a more distant relationship to their older children (due to heavy methamphetamine use), and a closer relationship to their youngest children during their more stable post-methamphetamine lives. The starkest gender difference pertains to the behaviour of the other parent. For all but one of the males, their female partner or ex-partner consistently provided support in raising their children. However, only half of the female interviewees have been able to rely on a consistently supportive male partner or ex-partner. Likewise, the females are more likely to be the sole or main caregiver to one or more of the children born to an ex-partner.

\subsection{The Influence of Parenting on Drug Use}

Interviewees were then asked, "Do you think parenting influenced your drug use?" For three-quarters of the fathers and 11-of-the-12 mothers, parenting did influence their drug use (especially methamphetamine use). However, in only one case did parenting only contribute to increasing drug use; after Interview-15 
(male, 46-years-old) left his partner and two children, his methamphetamine use "accelerated" as he sought to "hide the hurt".

For half the parents, parenting contributed to both increase and decrease drug use, which was much more common for the mothers because of their greater parental responsibilities. For the three fathers, methamphetamine was used as a way to be a "more productive parent" (research by Lende et al., 2007, shows methamphetamine is commonly used to enhance social functioning). For example, methamphetamine allowed Interview-18 (male, 45-years-old) to work longer hours and be more productive, thereby making more money for the family. But as Interview-20 (male, 44-years-old) discovered, this "functional" mode of use was a "catch 22 " because it made them "unproductive later on" when they had to come down. This realization contributed to desistance and helps maintain the state of desistance. For the eight mothers, methamphetamine (and alcohol and/or cannabis) was used as a "release" or "escape" or "stress relief" to help "deal with my kids" when "a bored and tired stay-at-home mum". As found in similar research (Boeri, Harbry, \& Gibson, 2009), methamphetamine provided energy to perform house chores. Additionally, it also helped with post-natal depression, or dealing with a delinquent child, or losing a child (whether in a custody dispute or a tragic accident). These female interviewees then decreased or quit methamphetamine use when: she became pregnant; she realized her children "didn't deserve this" lifestyle; her daughter told her she "hated meth"; her partner threatened to take their daughter away; or she desired to get her child back from state care.

For half the parents, parenting contributed to only decreasing drug use, which was more common for the fathers because of fewer parental responsibilities. For the eight fathers, becoming a father or wanting to be a good father or good role model "pushed" them or gave them "consideration" to "reduce, or try and keep it reduced". For Interview-35 (male, 23-years-old), his young daughter is a "good influence to not use" methamphetamine. For Interview-25 (male, 41-years-old), his young son rejected him because "he could pick it up that I wasn't normal", and this shock was "one of the things that made me want to get off it and get clean". Likewise for the three mothers, their children's wellbeing provided a reason to desist and to maintain the state of desistance. Interview-8 (female, 49-years-old) would spend the whole day smoking methamphetamine in the bedroom with her partner and friends, thereby neglecting her son and daughter. It took being confronted by her hungry and angry daughter for her to "realise" "what the fuck am I doing?" Additionally, the two daughters of Interview-24 (female, 42-years-old) "were the pivotal point of why I had to stop, otherwise I probably wouldn't have stopped".

\subsection{The Influence of Drug Use on Parenting}

Interviewees were then asked, "Do you think your drug use impacted upon your parenting and your relationship with your children?" Drug use influenced parenting for two-thirds of the fathers and all the mothers. However, in only one 
case was this influence only positive; Interview-28 (male, 38-years-old) vigilantly uses his "past experience" with drugs to make sure his children "are not going to have that sort of lifestyle". For 20-of-the-23, drug use had only a negative influence on parenting. For 7-of-the-10 fathers, methamphetamine was the only or main drug involved. Their methamphetamine use, but especially the comedown period, resulted in them neglecting their parenting duties and impacted upon attachment and emotional attunement. When present they would often be "vacant" or the time spent with their children was "false time" because they were "pretty fucked up on meth". For example, the 18-month-old son of Interview-25 (male, 41-years-old) "was picking up on my vibes" and would "kick and push me away". Reflecting back, some feel "gutted with myself" for this behaviour and now wish they had "given them more time" on "the things that mattered".

For the 12 mothers, in all but one case methamphetamine was the main drug involved. For most, methamphetamine use led to them being a "very bad parent" and an "extremely bad influence" on their children. The children could be "pretty much neglected", or because the methamphetamine comedown made them feel "dead inside" or "angry" or act "real erratic" then they found their children "annoying" and so were unable to be emotionally attuned to them. Interview-8 (female, 49-years-old) would take her anger out on her young son, and after becoming "scared I was going to kill him" asked her mother to care for him. Interview-5 (female, 50-years-old) simply said, "It is hard being fried [on methamphetamine] and trying to look after a baby". Post-methamphetamine use, they feel "devastated" about their methamphetamine-influenced conduct.

Finally, there is a clear gender divide in regards to the severity of the impact their drug use had on their children. For 7-of-the-10 fathers the negative impact was mild-or-medium and short-or-medium term, whereas for 8-of-the-12 mothers the negative impact was both severe and long-term. While for most fathers methamphetamine use "drew me away from parenting" for a period, for most mothers methamphetamine use "had a huge impact on my children's lives". For all eight, they were either separated from or gave up or lost custody of at least one child for an extended period of time. Interview-3 (female, 53-years-old) would "fly off the handle" at her daughter, who, in reaction, "started to rebel" before age eleven and ended up in state care. Likewise, the two daughters of Interview-24 (female, 42-years-old) "are suffering now from my addiction". Both have been in therapy, and her eldest daughter has "mental issues, depression and anxiety". For Interview-30 (female, 36-years-old), heavy methamphetamine use during pregnancy and post-birth, coupled with post-natal depression, a criminal lifestyle and multiple prison sentences, all impacted heavily on her estranged eldest daughter who is "really fucked up" with various "issues", including “ $A D H D$ ".

\section{Discussion and Conclusion}

According to Laub and Sampson's theory, marital stability and parental attach- 
ment should be significantly related to changes in illegal drug use. Simply, the stronger the adult bonds to marriage and parenting, the less illegal drug use. Conversely, being single, separated, divorced or in an unstable relationship and weakly attached to children will influence continued use. It can also be assumed that illegal drug use will negatively influence the relationship and parenting, but this impact will be more pronounced within relatively unstable relationships and weaker parent-child relations. The findings presented here indicate mixed support for the theory; support is weaker for romantic relationships (especially females) yet stronger for parenting. Compared to relationships, parenting is much less likely to increase illegal drug use, and much more likely to decrease illegal drug use.

As expected, all females in a relatively unstable relationship saw the relationship contribute to increased use. However, that is true for only half of the males in relatively unstable relationships. Likewise, in all but three cases drug use had a negative influence on a serious relationship. However, illegal drug use also had a partially positive influence on half the stable marriages (it helped to strengthen their marriage), and a third of the unstable relationships (they were more loving when high on methamphetamine). Overall, methamphetamine exerted the most negative influence on both relationships and parenting. Methamphetamine played a key role in greatly contributing to the relationship almost terminating or terminating, and also contributed disproportionately to conflict, abuse and emotional and/or physical distance. These negative outcomes were less pronounced for those in stable marriages, indicating that marriage helps protect against the negative side-effects of methamphetamine use. Likewise, for those in stable marriages, the impact of their drug use on their children was less severe and more short-term.

Moreover, the relationship helped limit or decrease drug use for over half the interviewees. However, this decrease was just as likely to occur whether the relationship was unstable or stable. Additionally, in a quarter of the cases, it was an adverse experience which helped decrease use (the female's partner was controlling or abusive, or the male interviewee either abused or cheated on his partner).

As expected, over half the males were in a relatively stable marriage relationship at the time of the interview, while almost a quarter were in a stable cohabiting relationship. Additionally, two-thirds involved in relatively unstable relationships were able to find a relatively stable marriage or relationship post-methamphetamine use. However, four entered this relationship after they had desisted from methamphetamine use. Unexpectedly, only three females were married and two were in a cohabiting relationship at the time of the interview, whereas over two-thirds were single. Likewise, only one involved in relatively unstable relationships was able to find a stable relationship post-methamphetamine use. Overall, the females are more likely to have never married and to have divorced, and much more likely to be single. Nevertheless, all managed to desist from methamphetamine use. Similarly, despite only one Māori interviewee being in a long-term stable relationship, two having divorced, 
seven yet to marry, and four being single, all managed to desist from methamphetamine use. In fact, all thirty-five desisted from methamphetamine use yet one-third of the males and half the females have never married, while seven never had children (and four never married nor had children). In addition, 7-of-the-13 married at the time of the interview was in a relatively stable long-term marriage before, during and after methamphetamine use. And in only one case did a stable marriage only exert a positive influence on decreasing methamphetamine use, whereas 6-of-the- 8 long-term stable marriages contributed in some way to increase illegal drug use.

Regarding parenting, two-thirds had children outside of wedlock, almost half had children with multiple partners, and over half did not have a consistently close relationship with some or all children. Such circumstances (more common for the females) are conducive to continued drug use. As expected, all except one in a stable marriage had a consistently close relationship with all their children, whereas this is true for only 6-of-the- 21 in unstable relationships. For almost all those with children, their illegal drug use (but especially methamphetamine) had only a negative influence on parenting. And for all but one of the parents, parenting expectedly contributed to decrease or desist from illegal drug use (especially methamphetamine). They either realized the negative impact their drug use has having on their children, or they desired to be a better parent. Unfortunately for twelve parents their prior immersion in the drug-user role had already inflicted severe damage on their relationship with some or all their children. Fortunately, some or all their children are now receiving appropriate parenting as their more stable post-methamphetamine lives enables them to fulfil their conventional role-related behaviour. As the aforementioned 2018 government inquiry into mental health and addiction stated, relationships with family members "give lives meaning and provide a potential path back to wholeness" ( $\mathrm{Pa}$ terson et al., 2018: p. 46).

Aotearoa/New Zealand society is considered one of the most welcoming for gender equality (Schwab et al., 2016). But due to female interviewees encountering much greater adversity in their romantic relationships and parenting, the findings presented here reveals the continuity of male dominance, where one in three Aotearoa/New Zealand women are estimated to have experienced more than one type of intimate partner violence (Fanslow \& Robinson, 2011). For example, all but one female interviewee was a victim of domestic violence, almost three-times as many were cheated on by their partner, only half could rely on a consistently supportive male partner or ex-partner to help raise their children, and they were more likely to be the sole or main caregiver to one or more of her and her ex-partner's children. Overall, the male partner was more likely to influence increased drug use among the female partner, whereas the female partner was more likely to influence decreased drug use among the male partner. In fact, only male interviewees had a partner who provided noticeable support to help them either decrease or desist from drug use. Such adversity illuminates one of the main findings from the Harvard Study of Adult Development: a lov- 
ing attachment relationship "is what matters most in life" (Vaillant, 2012: p. 191).

\section{Conflicts of Interest}

The author declares no conflicts of interest regarding the publication of this paper.

\section{References}

Bax, T. (2021). The Life-Course of Methamphetamine Users in Aotearoa/New Zealand: School, Friendship and Work. Journal of Criminology. https://doi.org/10.1177\%2F26338076211017180

Bax, T. (Forthcoming). The Adverse Childhood Experiences of Methamphetamine Users in Aotearoa/New Zealand.

Becker, H. (1963). Outsiders: Studies in the Sociology of Deviance. New York, NY: Free Press.

Biernacki, P. (1986). Pathways from Heroin Addiction: Recovery without Treatment. Philadelphia, PA: Temple University Press.

Boeri, M. (2004). "Hell, I'm An Addict, But I Ain't No Junkie”: An Ethnographic Analysis of Aging Heroin Users. Human Organization, 63, 236-245. https://doi.org/10.17730/humo.63.2.p36eqah3w46pn8t2

Boeri, M., \& Whalen T. (2012). Older Drug Users: A Life Course Study of Turning Points in Drug Use, 2009-2010. Ann Arbor, MI: Inter-University Consortium for Political and Social Research. https://doi.org/10.3886/ICPSR34296.v1

Boeri, M., Harbry, L., \& Gibson, D. (2009). A Qualitative Exploration of Trajectories among Suburban Users of Methamphetamine. Journal of Ethnographic \& Qualitative Research, 3, 139-151.

Boeri, M., Sterk, C E., \& Elifson. K. W. (2006). Baby Boomer Drug Users: Career Phases, Social Control, and Social Learning Theory. Sociological Inquiry, 76, 264-291. https://doi.org/10.1111/j.1475-682X.2006.00154.x

Boshears, P., Boeri, M., \& Harbry, L. (2011). Addiction and Sociality: Perspectives from Methamphetamine Users in Suburban USA. Addiction Research and Theory, 19, 289-301. https://doi.org/10.3109/16066359.2011.566654

Clayton, R. (2017a). Divorce Rate Declining as Kiwis Marry Later in Life. Stuff.co.nz. https://www.stuff.co.nz/life-style/love-sex/88235010/divorce-rate-declining-as-kiwis-m arry-later-in-life

Clayton, T. (2017b). Kiwi Criminals Deported from Australia Strengthening Gangs. New Zealand Herald.

https://www.nzherald.co.nz/nz/kiwi-criminals-deported-from-australia-strengtheninggangs/ZURZHR4WPC2J2N5HBF3GFBTLGQ/

Curran, P. J., Muthen, B. O., \& Harford, T. C. (1998). The Influence of Changes in Marital Status on Developmental Trajectories of Alcohol Use in Young Adults. Journal of Studies on Alcohol, 59, 647-658. https://doi.org/10.15288/jsa.1998.59.647

DePaulo, B. (2019). Around the World, Marriage Is Declining, Singles Are Rising. Psychology Today.

https://www.psychologytoday.com/us/blog/living-single/201908/around-the-world-ma rriage-is-declining-singles-are-rising

Fanslow, J. L., \& Robinson, E. M. (2011). Sticks, Stones, or Words? Counting the Preva- 
lence of Different Types of Intimate Partner Violence Reported by New Zealand Women. Journal of Aggression, Maltreatment \& Trauma, 20, 741-759. https://doi.org/10.1080/10926771.2011.608221

Giele, J. Z., \& Elder, G. H. (1998). Life Course Research. Development of a Field. In J. Z. Giele, \& G. H. Elder (Eds.), Methods of Life Course Research: Qualitative and Quantitative Approaches (pp. 5-27). Thousand Oaks, CA: Sage Publications. https://doi.org/10.4135/9781483348919.n1

Granfield, R., \& Cloud, W. (1996). The Elephant That No One Sees: Natural Recovery among Middle-Class Addicts. Journal of Drug Issues, 26, 45-61. https://doi.org/10.1177\%2F002204269602600104

Granfield, R., \& Cloud, W. (2001). Social Context and "Natural Recovery": The Role of Social Capital in the Resolution of Drug-Associated Problems. Substance Use \& Misuse, 36, 1543-1570. https://doi.org/10.1081/JA-100106963

Horney, J., Osgood, W., \& Marshall, I. H. (1995). Criminal Careers in the Short-Term: Intra-Individual Variability in Crime and Its Relation to Local Life Circumstances. American Sociological Review, 60, 655-673. https://doi.org/10.2307/2096316

Hser, Y, Longshore, D., \& Anglin, M. D. (2007). The Life Course Perspective on Drug Use: A Conceptual Framework for Understanding Drug Use Trajectories. Evaluation Review, 31, 515-547. https://doi.org/10.1177\%2F0193841X07307316

Johnson, A. (2018). Kei a Tatou. It Is US: State of the Nation Report 2018. Wellington: The Salvation Army Social Policy and Parliamentary Unit.

Laub, J. H., \& Sampson, R. J. (2003). Shared Beginnings, Divergent Lives: Delinquent Boys to Age 70. Cambridge, MA; London: Harvard University Press.

Lende, D. H., Leonard, T., Sterk, C. E., \& Elifson. K. (2007). Functional Methamphetamine Use: The Insider's Perspective. Addiction Research and Theory, 15, 465-477. https://doi.org/10.1080/16066350701284552

Levy, J., \& Anderson, T. (2005). The Drug Career of the Older Injector. Addiction Research and Theory, 13, 245-258. https://doi.org/10.1080/16066350500053554

Milne, B., Byun, U., \& Lee, A. (2013). New Zealand Socio-Economic Index, 2006. Wellington: Statistics New Zealand.

Ministry of Health. (2014). Amphetamine Use 2015/16: Aotearoa/New Zealand Health Survey. Wellington: Ministry of Health.

Ministry of Health. (2016). Amphetamine Use 2015/16: Aotearoa/New Zealand Health Survey. Wellington: Ministry of Health.

Ministry of Health. (2019a). Amphetamine Use 2018/19: Aotearoa/New Zealand Health Survey. Wellington: Ministry of Health.

Ministry of Health. (2019b). Heterosexual Sexual Behaviour: Findings from the 2014/15 Aotearoa/New Zealand Health Survey. Wellington: Ministry of Health.

Moneyham, L., \& Connor, A. (1995). The Road in and out of Homelessness: Perceptions of Recovering Substance Abusers. Journal of the Association of Nurses of AIDS Care, 6, 11-19. https://doi.org/10.1016/S1055-3290(05)80018-4

Paterson, R., Durie, M., Disley, B., Rangihuna, D., Tiatia-Seath, J., \& Tualamali' I, J. (2018). He Ara Oranga. Report of the Government Inquiry into Mental Health and Addiction. Wellington: Ministry of Health.

Patterson, G. (1980). Children Who Steal. In T. Hirschi, \& M. Gottfredson (Eds.), Understanding Crime: Current Theory and Research (pp. 73-90). Beverly Hills, CA: Sage

Peele, S. (1989). The Diseasing of America: Addiction Treatment out of Control. Lexing- 
ton, MA: Lexington Books.

Peele, S., \& Rhoads, Z. (2019). Outgrowing Addiction-With Common Sense Instead of "Disease" Therapy. Hinesburg, VT: Upper Access Books.

Policy Advisory Group (2009). Tackling Methamphetamine: An Action Plan. Wellington: Department of the Prime Minister and Cabinet.

Popenoe, D. (1996). Life without Father. New York, NY: Free Press

Roe, B., Beynon, C., Pickering, L., \& Duffy, P. (2010). Experiences of Drug Use and Ageing: Health, Quality of Life, Relationship and Service Implications. Journal of Advanced Nursing, 66, 1968-1979. https://doi.org/10.1111/j.1365-2648.2010.05378.x

Sampson, R. J., \& Laub, J. H. (1993). Crime in the Making: Pathways and Turning Points through Life. Crime \& Delinquency, 39, 396. https://doi.org/10.1177\%2F0011128793039003010

Schwab, K., Zahidi, S., Alexander Leopold, T., Ratcheva, V., Hausmann, R., \& Tyson, L. D. (2016). Global Gender Gap Report, 2016. Geneva: World Economic Forum.

Shover, N. (1996). Great Pretenders: Pursuits and Careers of Persistent Thieves. Boulder, CO: Westview Press.

Teruya, C., \& Hser, Y. (2010). Turning Points in the Life Course: Current Findings and Future Directions in Drug Use Research. Current Drug Abuse Review, 3, 189-195. https://doi.org/10.2174/1874473711003030189

Vaillant, G. (2012). Triumphs of Experience: The Men of the Harvard Grant Study. Cambridge, MA; London: Harvard University Press. https://doi.org/10.4159/harvard.9780674067424

Warr, M. (1998). Life-Course Transitions and Desistance from Crime. Criminology, 36, 183-216. https://doi.org/10.1111/j.1745-9125.1998.tb01246.x

White Riley, M. (1998). A Life Course Approach, Autobiographical Notes. In J. Z. Giele, \& G. H. Elder (Eds.), Methods of Life Course Research: Qualitative and Quantitative Approaches (pp. 28-51). Thousand Oaks, CA: Sage Publications. https://doi.org/10.4135/9781483348919.n2

Wilkins, C., Prasad, J., Wong, K. Y., \& Rychert, M. (2017). Recent Trends in Illegal Drug Use in Aotearoa/New Zealand, 2006-2016. Findings from the Illicit Drug Monitoring System. Auckland: SHORE and Whariki Research Centre, College of Health, Massey University. 